\title{
Exploring the Role of Motivation in English Language Teaching: Learners and Teachers Perspective
}

\author{
Muhammad Ajmal ${ }^{1}$, Muhammed Salim Keezhata ${ }^{2, *}$, Ghulam Mujtaba Yasir ${ }^{3}$ \& Sohaib Alam ${ }^{4}$ \\ ${ }^{1}$ Assistant Professor of English, Department of English, University of Lahore, Pakistan \\ ${ }^{2}$ Assistant Professor, Department of English, College of Science and Humanities in Al-Kharj \\ Prince Sattam Bin Abdulaziz University, Saudi Arabia. \\ ${ }^{3}$ Assistant Professor, Department of English, Ghazi University, DG Khan, Pakistan \\ ${ }^{4}$ Assistant Professor, Department of English, College of Science and Humanities, \\ Prince Sattam Bin Abdulaziz University, Saudi Arabia.
}

*Corresponding Author:Muhammed Salim Keezhata, m.keezhatta@psau.edu.sa

\begin{abstract}
This study aims at exploring and investigating the role of motivation in learning and teaching of English language. It highlights the fact if extrinsic motivation is likely to have an impact on the learning process of a student stronger than intrinsic motivation, or both types of motivations have a significant role to play in the process. The study also focuses on the role of a teacher in building a conducive environment to sustain a healthy competition in teaching a second language. The questionnaire was sent to undergraduate students of 2 universities by using Google forms. The sample size for this research population was 60 . There were a total of 19 (31.7\%) male respondents and $41(68.3 \%)$ female respondents. The results conclude that students' guardians have a significant role to play in learning a new language. The primary method, for most students, to learn English language was through entertainment media such as television and movies. A significant motivator for students was the opinion of other people. There was a moderate, positive correlation between the two variables namely extrinsic and intrinsic motivation $[r=.345, n=60, p<.0005]$. This shows that the two types of motivations are not mutually exclusive but can co-exist as they did in our sample. Both extrinsic and intrinsic motivations are crucial in the development of effective pedagogical practices.
\end{abstract}

Keywords:

English Language Teaching, extrinsic motivation, intrinsic motivation, entertainment media, under graduate students Article Received: 18 October 2020, Revised: 3 November 2020, Accepted: 24 December 2020

\section{Background of the Study}

Motivation is believed to be something that liaises directly with behavior. People decide on performing certain tasks or setting certain goals and then achieving those goals. But what goes on in between setting the target and achieving it? One can assume that motivation plays a vital role because of its immense value in the process of learning, and influences their success rate, when people choose to learn English language. A person's internal drive can pave the passage to success. A person's internal and external desires shape the way to progress towards their goals. When it comes to learning a language, motivation can be perceived in the form of external and internal motivation. This desire to learn a new language might stem from personal achievement, personal goals, personal inspiration and perhaps just a need to grow intellectually with or without any external reward.

One of the ever first theories to touch upon the subject of motivation was proponded by Sigmund Freud, who wrote about the parts of a person's subconscious. He came up with the psychoanalytic theory which focuses on the desires of people and the drives that force them to achieve or succumb to such desires. It was then the work of B.F Skinner, Rotter's [18] social learning theory and lastly, Atkinson et al [2] which then further 
clarified the things. They wrote about stimulation and reinforcement wherein a behavior is likely to be repeated if it is rewarded in some way (Skinner). Thus, motivation became the center of attention and a key element towards progress.

Saudi Arabia'snational language is Arabic and with it, English was set as the official language. Despite being their official language, a large chunk of the population cannot read, write or speak English as per foreign standards of education. At the same time, the diversity present in Saudi Arabia means that students flock to urban areas in order to gain formal education, and owing to their different linguistic and dialectic backgrounds, learning English seems to be a hard net to crack for them. Those who come from backgrounds where English is taught in their school education, don't necessarily use their general education courses as a means to learn the language, whereas those who come from different linguistic backgrounds need to learn English because the books, the lectures, and the medium of communication and information, being in English. It means that their learning English becomes a pre requisite. The other factors involved include receiving good grades and earning a better CGPA, which is an indicator of a student's performance in the university and later might lead to secure a good job or internship in a respectable institution.

In motivating students to learn, teachers become central figures. More often, it is up to the teacher to remove any hostility that might arise between those who know English well and those who have trouble with it and to ensure that the classroom is a safe, nourishing environment meant only for learning without any shame attached. Often, teachers themselves ridicule the students if they seem to experience difficulties, instead of helping them overcome these difficulties. Students are more likely to succeed in not just learning languages but other tasks as well, if they are encouraged, and given the right push and most importantly, if they experience the right kind of internal and external motivation. Teachers are key players when it comes to keeping the learners as engaged as possible within the classroom so that they can experience high level of both intrinsic and extrinsic motivation. In learning a language, Gardner's description can be used which involves effort, desire and most importantly a favorable disposition towards this language. A favorable disposition may not be achieved if past experiences with learning the language have been negative in nature or have led to distress caused by either teachers or peers.

Both internal and external factors are at work regarding Learners' motivation. For instance, internal motivation might mean that a language is being learned simply to be able to communicate in that language. The learner might have picked it up as a fun hobby, may be they like watching foreign films and television and have decided to learn a language instead of using subtitles, and it may prove a joyous thing for them to do so. At the same time, external motivation could be that of a reward; perhaps the learner is preparing for an exam in a foreign country, which could mean better opportunities in life, a better career or different ways to make money. In this kind of high stakes situation, it is likely that the learner is trying to learn a language out of necessity and survival. Effort alone is not what drives the learner to accomplish the task of learning a new language; it is both the satisfaction of achieving this goal, and the effort and the presence of desire that effects the learner's motivation. However, motivation can be difficult to define in exact terms given the vast literature that exists on studying it and the various perspectives on it, but one thing is certain, it definitely has a key role in the way the learners strategize and push forward.

In Saudi Arabia, the medium of instruction is English. It is also the language which is used in the text books, in exams, and even taught in higher 
academic institutions. English is also taught as a compulsory subject from the lowest academic grade to the highest; even universities have basic and compulsory English courses to make the learners proficient in English and to enable them to write research papers, to communicate and to write creatively. Many students with strong English background, while speaking, prefer English to other languages because they feel at ease and confident in expressing their ideas in it, but those who have not had similar educational backgrounds might forego socializing in fear of not being able to communicate thoroughly or fluently in English. This might cause them lose confidence in their own abilities and thus, develop a low level of motivation. This study spotlights the ways in which motivation influences a student's abilities to learn English and the vital part played by teachers in assuming the role of motivators. In Saudi Arabia, a number of students belong to non-English speaking backgrounds and although they might have different motivation to learn the language, at the root of their progress and desire to master it lies their self-interest. This study focuses on how well motivation works in the lives of second language learners. It compares their level of motivation with their performance.

\subsection{Research Questions}

This study endeavors to answer the following research questions:

1) Are there any significant differences in opinion about the role of motivational factors in terms of teachers and learners' perception?

2) What are the motivational factors influencing the academic achievement of the participants?

\section{Literature Review}

The first sign of trouble, when studying motivation, arises when it becomes difficult to describe it. Various criteria to define motivation exist with conflicts among writers, thinker and psychologists but the crux of agreement rests upon the difficulty and necessity to reach a consensual definition. Brown [6] remarked about the existing definitions of motivation being too vague to be used as a substantial instrument, wrecked with conflict and arguments about its origins and nature and its being a "behavioral determinant." According to Bolles [5], that while there is little consensus upon the defining criteria of motivation, most definitions given depend on the contributor's own sense of commitment to the theory than motivation itself. Other theorists such as Bunnel and Verplanck [22] have proposed to desert the concept in its entirety.

Atkinson and Birch (1978) have highlighted the four languages of motivation that have been accentuated by psychologists in their definitions of motivation: neuropsychological, mathematical, experiential, and behavioral. Abraham Maslow [13] writes, "The original criterion of motivation and the one that is still used by all human beings except behavioral psychologists is the subjective one. I am motivated when I feel desire or want or yearning or wish or lack." Another definition proposed by Dalbir Bindra and Jane Stewart [4] describes motivation to be "Any goal-directed action is instigated by a central motivational state, which itself is created by an interaction within the brain between the neural consequences of bodily organismic states ('drives') and neural consequences of environmental incentives ('reinforcers')."

\subsection{Theories of Motivation}

Stewart [4] came up with a theory of motivation that suggested people experience motivation when their needs have been met. $\mathrm{He}$ theorized a pyramid of needs which progresses from the lowest tier of basic needs to the highest form of their manifestation which was framed as Selfactualization. In order to progress to the higher needs, also known as growth and being needs, one first has to fulfill the lower levels or the deficiency needs. The lowest level of the pyramid displays basic, physiological needs such as food, water, sleep 
and shelter, sex and warmth. The desire to fulfill these needs increases proportionally to the duration of their absence. The body performs at optimal function if these needs are met. The second level is based upon security. This could be financial security or job security, feeling safe and secure in one's own body, house or residence security, health etc. These needs are based around experiencing some sort of control, predictability and order in one's life. The third level takes into consideration the need to be loved and belongingness. This is centered on the society we live in, the relationships we form, romantic or platonic, religious affiliations, workplace socialization etc. Interpersonal relationships act as an instrument for motivation.

Another theory of motivation is Skinner's Reinforcement which is applicable on the area of communication. This means that people like to be reinforced upon their ideas and their beliefs and do not like to be told that they are wrong. This was analyzed upon the criteria that organisms reacted to certain stimuli. These stimuli were present in their environment. One of the stimuli that affected the organisms the most was known as the "Cue". This cue generated a response in the organism. However, it is said that a response is never complete without a reaction being given from the environment itself. The environment, it was then found out by Skinner, gave a reaction which was then termed as reinforcement. This kind of a reaction is not the sole reaction but a mere part of a number of reactions This meant that there are other reactions as well but Skinner focuses on the reinforcement and formulates a motivational theory regarding the act of reinforcement by the environment and its result in the production of pleasure in the organism; namely human.

\subsection{Intrinsic and Extrinsic Motivation}

In a very basic sense, motivation is the need or desire behind everything we do or see being done around us. Motivation can be either intrinsic or extrinsic. Without it, our life would be bland and we'd just be living like robots. Doing what is told to us and never striving to do better. For instance, when parents need to motivate their children to study hard, they give them certain incentives. This is called extrinsic motivation. The word intrinsic itself refers to something that is inherent by nature. The world is synonymously used with inner, which refers something from within. Unlike extrinsic motivation, intrinsic motivation doesn't need any external incentive. It is inherent. When it comes to intrinsic motivation, what propels people into action is their own will and self-determination. For instance, when a child studies hard because he or she likes to study and enjoy learning thing, the motivation behind is intrinsic in kind. The reward is a sense of accomplishment rather than promised goods. Intrinsic motivation is ideally the best motivation because then the behavior isn't manipulated by other incentives. Because when incentives are given, the person is more like a pawn doing things at the will of others. (deCharms, [7]. There are several theories of intrinsic motivation but the one most widely quoted and cited is that of Self- Determination theory (SDT). This theory was developed by Edward Deci and Richard Ryan [8]. According to this theory all humans have three psychological needs and these are the need to feel competent, related and autonomous. As stated by the theory, these needs are what give birth to intrinsic motivation. It is when one feels autonomous, competent and self-determined and one pursues an interest of ones. The authors go on to say that when people feel competent, autonomous and self-determined, they will freely seek what interests them. For instance, while playing games when we're upgraded to the next level we feel competent to try and pass the new level to reach the highest level there is. This sense of competence is what keeps us focused on playing the game and again. Intrinsic motivation is the motivation present in the act of learning English as a second language itself whereas extrinsic motivation is any such 
motivation that goes beyond and is aimed at achieving something through the act of learning, rather than learning itself ,Vallerand et al, [21].

Ilić [9] found that from those learning English as a second language in both high school and university, there was generally a lack of intrinsic motivation present. Many of the students believed in the activity rewarding them in the future whereas not many of them had interest or a relatively high level of enjoyment when it came to learning the language. Some minor differences were found such as women enjoying it more than men but these, by and large, were negligible due to any such differences being minimal. Quadir [12] found that students who were intrinsically motivated were more likely to enjoy the language they were being taught which led to an increase in the probability that they would continue to learn English as a second language and that there was a significant difference in the scores achieved in proficiency tests by those that were intrinsically motivated and those that were extrinsically motivated. It was also found that students that were both intrinsically and extrinsically motivated would be more adept at reading and other activities, Tercanlioglu, [19].

Samejon [17] discovered that most students viewed learning English as a second language as a means to achieve far reaching goals, such as academic ambitions or climbing up the economic ladder, thereby meaning that they were more extrinsically motivated to the rewards that they could reap from the act of learning English. The effects of pedagogy on learning was also found to be immensely important to the degree of motivation that students had for learning English as a second language and that the teacher was instrumental in the way the students in the study approached the activity. Niazi and Zahid [15] found that English learning of students was both motivated extrinsically and intrinsically, however most of them saw the activity as being necessary in order to procure higher grades in their academic career and also be more appreciated by their general peers therefore they were found to be more extrinsically motivated. This again represents how many students view the rewards of learning to lie beyond the activity in itself and is representative of society where those that speak well in English to avail certain advantages. It also represents the lack of the environment that is necessary for properly developing intrinsic motivation in students.

\section{Research Design}

\subsection{Research Approach and Design}

The researchers believed that a mixed method approach towards this study would prove to be more in depth, valid and reliable. Both qualitative and quantitative methods were employed to collect primary data from students and teachers alike. A questionnaire was adapted from Quadir's [16] research to fit the study. This questionnaire was circulated among the students. Given that the data meant to be collected from the teachers was more demanding and comprehensive, the researchers chose to interview the teachers.

\subsection{Population and Sample}

The research was designed to be conducted on the formally educated students and practicing teachers of Saudi Arabia. Data was collected from two public and a private sector universities of the Riyadh region. Students who had to formally learn English as a foreign language were selected for the study. Teachers who had specific experience in teaching English Language to non-native speakers were chosen. The sampling method was that of convenience sampling. The sample size was 60 students.

\subsection{Data Collection Procedure}

Due to the Covid-19 pandemic and the lockdown, the research was conducted on online platforms. The researchers created the survey on Google Forms and sent it on to various online, social media platforms such as Facebook, Twitter, LinkedIn, WhatsApp. The data collected from all of the 
surveys was quantified onto Excel and then SPSS to be analyzed statistically. Teachers who volunteered to be a part of the study were reached out to on the phone. The interviews were recorded and then transcribed.

\subsection{Data Analysis}

Data Analysis was conducted through entering the data from the student survey onto Microsoft Excel and then IBM SPSS. The data from the interviews, after transcription, was examined by the researchers to perform a thematic analysis. After the transcription, initial codes were generated along with their identification of initial themes. The themes and codes were thoroughly edited and proofread for refinement and finally published.

\subsection{Timeline}

This research began in January. The initial data collection was meant to occur in March 2020, but due to the pandemic and alarming rise in the number of cases, a lockdown ensued. The researchers had to postpone the data collection till
July. The interviews were conducted and the data were collected between July and September 2020.

\subsection{Instruments}

The survey that was administered to the students was an adoption of Quadir's [16] research, "A Comparative Study of English and Non-English Major University Students' Motivation to Learn English Oral Communication." The researchers conducted a study to discover if there were any differences in motivation to learn English language between students of English and non-English "major" students enrolled in universities.

\section{Data Analysis and Discussion of Findings}

\subsection{Results and Discussion}

The questionnaire was sent to undergraduate students of a public and a private sector universities using Google forms. The sample size for this research was 60 . There were total $19(31.7 \%)$ male respondents and $41(68.3 \%)$ female respondents. The table one describes the gender distribution of the participants in the study.

Table 1. Gender distribution of the sample

\begin{tabular}{ccc}
\hline Gender & Frequency & Percentage \\
\hline Male & 19 & $31.7 \%$ \\
Female & 41 & $68.3 \%$ \\
Total & 60 & $100 \%$ \\
\hline
\end{tabular}

Majority of the participants were in their final years. The sample had $40(66.7 \%)$ fourth year, $15(25.0 \%)$ third year, $4(6.7 \%)$ second year and $1(1.7 \%)$ first year students. Table 2 describes the distribution of academic years of students.

Table 2. Academic years of the sample

\begin{tabular}{lll}
\hline Academic year & Frequency & Percentage \\
\hline First Year & 1 & $1.7 \%$ \\
Second Year & 4 & $6.7 \%$ \\
Third Year & 15 & $25.0 \%$ \\
Fourth year & 40 & $66.7 \%$ \\
\hline
\end{tabular}

Students from both public and private sector were sampled. However, there were more students from the private sector than the public sector. A total of $49(81.7 \%)$ participants were from a publicuniversity and only $11(18.3 \%)$ of the participants were from a private sector university. Table three describes the kind of universities the sample belonged to. 
Table 3. Type of university

\begin{tabular}{lll}
\hline University type & Frequency & Percentage \\
\hline Private sector & 11 & $18.3 \%$ \\
Public sector & 49 & $81.7 \%$ \\
Total & 60 & $100 \%$ \\
\hline
\end{tabular}

Majority of the participants reported learning English from Television and Movies followed by Books, communication with peers and English classes. This finding tells us that students learn English primarily from Television and movies and books, which are factors in the environment of the students compared to learning in the classroom and through communication. This can help us tailor our teaching methods and classrooms in a way that utilizes these methods more than rote memorization and mandatory learning and application of the grammar rules as these methods are what students find more effective in helping them learn. The following table (table 4) describes where the sample learnt English language from in detail:

Table 4. Sources of learning English

\begin{tabular}{lll}
\hline Source of learning & Frequency & Percentage \\
\hline Television/ Movies & 33 & $55.0 \%$ \\
Books & 17 & $28.3 \%$ \\
Communication with peers & 9 & $15.0 \%$ \\
English class & 1 & $1.7 \%$ \\
\hline
\end{tabular}

The top four most agreed upon items by the participants are summarized in the table below (table 5). This shows us that most students learn English because of the influence their guardians have on their lives and because guardians think it is important for their children to know English language. This also tells us that one of the most important reasons students get engaged in learning and improving their English is to be able to impress people around them. This could be the result of the participants being university students. Opinions of other people have more impact on university students. The third highest scoring item was "I am afraid people will laugh at me or mock me when I speak English", this result is consistent with the teacher's viewpoint that students are impacted by those around them and their behavior encourages or discourages students a lot.

Table 5. Top four most agreed upon items

\begin{tabular}{lll}
\hline Item & Mean & SD \\
\hline I am learning to speak English because my guardians want me to improve my & 3.88 & 1.16 \\
English skills. & 3.64 & 1.29 \\
I want to improve my English so that I can impress the people around me & 3.47 & 1.40 \\
I am afraid people will laugh at me or mock me when I speak in English & 3.40 & 0.94 \\
Speaking English is a hobby for me
\end{tabular}


The least four agreed upon statements by the participants are also summarized in the table below (table 6). The data shows that the least important factor for our participants is that they would be able to travel to new countries and communicate with foreigners. This was followed by "I believe learning better English will help me get a better job. It appears that our participants do not conform to the notion that learning better English gives you a better job.

Table 6. Top least four agreed upon items

\begin{tabular}{llll}
\hline Item & Mean & SD \\
\hline I want to learn English, so I am able to travel to new countries and & 2.43 & 1.55 \\
communicate with foreigners. & & \\
I believe learning better English will help me get a better job. & 2.63 & 1.51 \\
English proficiency is important for me & 2.65 & 1.30 \\
I enjoy speaking English very much. & 2.77 & 1.04 \\
\hline
\end{tabular}

Mean scores and standard deviations of the participants on the three subscales used in the research; intrinsic motivation (mean $=3.04$ ), extrinsic motivation (3.16) and anxiety (3.29) are summarized in the following table (Table 7). The highest score on these three subscales was in subscale Anxiety. This tells us more needs to be done in order to better deal with anxiety resulting from learning a new language.

Table 7. Mean scores on the subscales of intrinsic motivation, extrinsic motivation and anxiety

\begin{tabular}{lll}
\hline Subscale & Mean & SD \\
\hline Intrinsic Motivation & 3.04 & 0.78 \\
Extrinsic motivation & 3.16 & 0.93 \\
Anxiety & 3.29 & 1.15 \\
\hline
\end{tabular}

$\mathrm{T}$ tests were conducted to compare means on the three subscales of intrinsic motivation, extrinsic motivation and anxiety of male students and female students. Results show that there is no significant difference between the two genders on any of the scales. The following table (Table 8) describes the results of $t$-test on the three subscales of motivation of males and females from the sample.

Table 8. T-test results on the motivation subscales of Males and Females

\begin{tabular}{|c|c|c|c|c|c|c|}
\hline $\begin{array}{l}\text { Motivation } \\
\text { sub-scale }\end{array}$ & $\begin{array}{l}\text { Male } \\
\text { M }\end{array}$ & $\begin{array}{l}(n=19) \\
\text { SD }\end{array}$ & $\begin{array}{l}\text { Females } \\
\text { M }\end{array}$ & $\begin{array}{l}(n=41) \\
\text { SD }\end{array}$ & $t$-test & $\begin{array}{l}\text { Sig.(2- } \\
\text { tailed) }\end{array}$ \\
\hline $\begin{array}{l}\text { Intrinsic } \\
\text { Motivation }\end{array}$ & 3.28 & 0.67 & 2.92 & 0.81 & 1.81 & 0.077 \\
\hline $\begin{array}{l}\text { Extrinsic } \\
\text { Motivation }\end{array}$ & 3.21 & 1.06 & 41 & 3.13 & 0.26 & 0.794 \\
\hline Anxiety & 3.46 & 1.19 & 41 & 3.21 & 0.755 & 0.456 \\
\hline
\end{tabular}

$\mathrm{T}$ tests were conducted to compare means on intrinsic motivation, extrinsic motivation and anxiety subscales of students from private universities and public universities. Our research 
shows that there are no statistically significant differences in the anxiety, extrinsic and intrinsic motivation levels of students from these two groups. This tells us students in both types of universities have similar views on their experience with the English language. The results of this analysis are summarized in the following table (table 9):

Table 9. T-test results on the motivation subscales of students from Private and Public university students

\begin{tabular}{|c|c|c|c|c|c|c|}
\hline $\begin{array}{l}\text { Motivation } \\
\text { sub-scale }\end{array}$ & $\begin{array}{l}\text { Public } \\
\text { M }\end{array}$ & $\begin{array}{l}(n=49) \\
\mathrm{SD}\end{array}$ & $\begin{array}{l}\text { Private } \\
\text { M }\end{array}$ & $\begin{array}{l}(n=11) \\
\mathrm{SD}\end{array}$ & $t$-test & $\begin{array}{l}\text { Sig.(2- } \\
\text { tailed) }\end{array}$ \\
\hline $\begin{array}{l}\text { Intrinsic } \\
\text { Motivation }\end{array}$ & 3.05 & 0.77 & 3.00 & 0.86 & 0.180 & 0.860 \\
\hline $\begin{array}{l}\text { Extrinsic } \\
\text { Motivation }\end{array}$ & 3.10 & 0.97 & 3.40 & 0.71 & -1.14 & 0.267 \\
\hline Anxiety & 3.27 & 1.11 & 3.36 & 1.34 & -0.20 & 0.843 \\
\hline
\end{tabular}

The relationship between extrinsic motivation (as measured by the extrinsic motivation subscale) and intrinsic motivation (as measured by the intrinsic motivation subscale) was investigated using Pearson product-moment correlation coefficient. Preliminary analyses were performed to ensure no violation of the assumptions of normality, linearity and homoscedasticity. There was a moderate, positive correlation between the two variables [ $r=.345, n=60, p<.0005]$. This goes on to show that the two types of motivation are not mutually exclusive but can co-exist as it did in our sample. Students were both intrinsically and extrinsically motivated. The following figure is a scatter plot of the correlation.

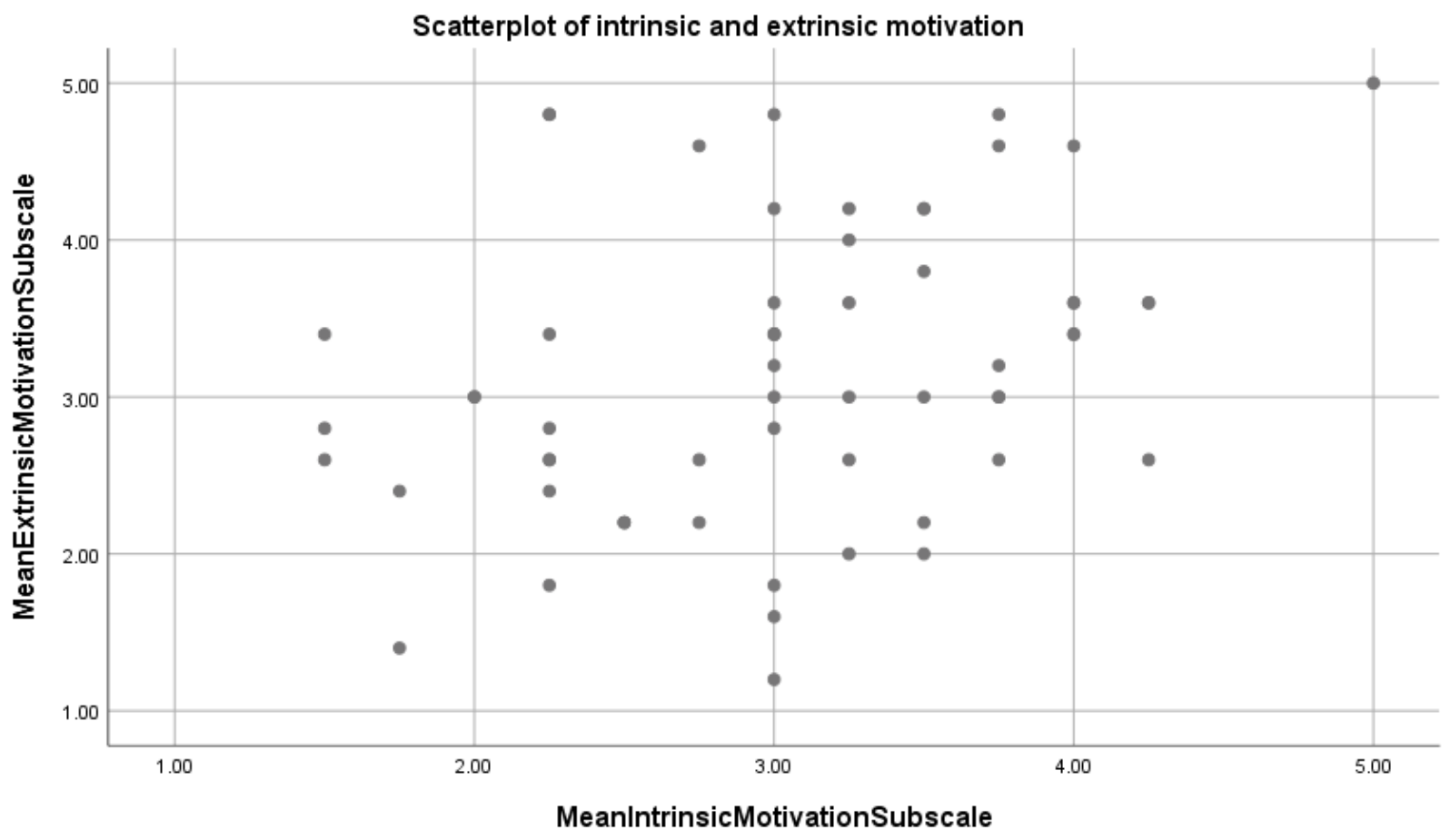

Figure 1: Scatter plot between Intrinsic and Extrinsic Motivation.

\subsection{Teachers' Response}


The teachers interviewed for the research were of the view that English language is very significant for student's success in today's world. They described English as the language that "linked the world" and believed English language is integral to learning and growth in every field. They felt it is important that students master the language as it guarantees access to knowledge, progress and innovation.

One of the interviewees shared that students are initially very shy and afraid to speak English in their class because of fear of judgment. They opined it is important for the teacher at this point to make sure that the students feel confident that the classroom is a safe space and they will not be mocked or laughed at upon trying to speak. Practicing English language was key to learning it and it is the teacher's responsibility to make sure as many students as possible are applying what they are learning in their normal routine conversations. The students are afraid of being judged over things like pronunciation, accent and vocabulary and this fear of being made fun of stops them from speaking altogether. The teacher went on to explain that students who are able to deal with the fear and practice what they are learning, do better in their class than those who do not speak. It is integral that teachers actively encourage students to participate while maintaining discipline in class so that no one makes fun of those who are trying to learn the language. "English is our second language after all, we do not need to be excellent, only need to improve our skill, when students keep trying to learn and overcome their fear of judgment, results follow" the teacher concluded.

According to the teachers, the material that engaged the students the most was the kind they found most effective in teaching English. Assignments that engaged student's life, plaque cards, illustrations, charts were some of the popular tools used by the sample. They also found small group exercises to be very successful in not just engaging them but also in understanding new concepts, "students know each other better, they know how to explain things to each other better, peers explaining to each other and then practicing the concept in small groups has been very effective for me."

The relationship of teacher and students shapes the learning process in great many ways according to the participants; "there should be respect, a willingness to learn and trust in the relationship" said one of the participants. They also focused on how the environment in the class should be friendly and welcoming and not harsh and off-putting. "the teacher needs to come down to the level of students and try to bring them up, that cannot be done unless you are a bit like a friend to them", according to one of the participants.

The teachers were divided about the best way to correct a student's mistake. One group was of the view that it should be mentioned to the entire class so that it serves as a learning experience of all students in the class. While the other group considered this approach to be rather harsh and thought it best to communicate the mistake to the student personally and making sure their privacy is maintained so they do not get discouraged from making the same mistake again. Teachers from both groups reported that their technique was working well for their students and saw no need to change it to the alternative.

Teachers believed that the motivation levels of the entire class and of individual students depend highly on the teachers. Technology was perceived as important for today's classroom by all teachers. "Today's world is changing every single day and technology is an important aspect of that change, embracing it is the best way to go about this today" Learning a new language opens up a new world for students, technology makes it possible for us to access, visualize and experience many aspects of the new world ourselves. All teachers were very receptive towards technology and believed it was 
the way forward in today's world and could help the students and the teachers quite significantly.

One common activity recommended by most of the teachers was to provide access to English entertainment to the students. The teachers who gave out this recommendation regularly invested in valuable resources such as buying DVDS with English movies and distributing them among the students. Half the teachers would hold discussion circles. The students were given the options of several movies that were selected based on their collective interests. They were asked to watch the movie and return to the classroom where they would then spend time discussing the movie in English and examine various accents and pronunciations. They also reported that as the students discovered new genres, they would learn different slang and pick up pop culture references that are not taught in formal classroom environments. They believed this made the students feel more integrated with their English-speaking friends and classmates by increasing conversation subjects.

\section{Conclusion}

All in all, this study concludes that the presence of both extrinsic and intrinsic motivation is necessary to help students overcome the challenges posed by learning a new language. The responsibility of teachers is also something that is undermined in academia. Most students do not feel comfortable reaching out to their instructors and informing them of any troubles that may arise when they try to learn a non-native language. Empathy and sensitivity training would take the student teacher relationship to the next level and aid in bringing a positive change in the classroom environment. The role of technology and diverse learning cannot be undermined. Students in Saudi Arabia are not encouraged to leave their textbooks and learn through television, movies, books and entertainment. Both parental and academic responses to this are discouraging. Those that report anxiety would have a better time of it if they were allowed to practice within a controlled and safe environment. This ensures that when they go out into the real world and use the skills they learn in classrooms; they will end up in getting more confident in their own abilities thus experiencing an amalgamation of extrinsic and intrinsic motivation. Although this study projects a positive correlation between the two types of motivation, reviewed literature displays findings that seem to suggest the prevalence of extrinsic motivation instead of intrinsic motivation. In this case, the way we teach students, not just in schools and programs that focus on learning languages, but in all other programs, have to be different than what is occurring. Perhaps, if students were taught to accept challenges more often, they would prefer to think of learning a new language as an achievement rather than a chore.

\section{REFERENCES}

[1] Atkinson, J. W., \& Birch, D. An introduction to motivation (2nd ed.). New York: Van Nostrand, 1978.

[2] Bernaus, M., \& Gardner, R. C. Teacher motivation strategies, student perceptions, student motivation, and English achievement. The Modern Language Journal, 92(3), 387401, 2008.

[3] Bindra, D., \& Stewart, J. Motivation (2nd ed.). Harmondsworth, Middlesex, England. Penguin Education, 1971.

[4] Bolles, R. C. Theory of motivation (2nd ed.). New York: Harper \& Row, 1975.

[5] Brown, J. S. Motivation of behavior. Prabhat Prakashan, 1961.

[6] deCharms, R. Personal causation: the internal affective determinants of behavior. New York: Academic Press, 1968.

[7] Deci EL, Ryan RM. Intrinsic Motivation. The Corsini Encyclopedia of Psychology. January 
2010.

doi:10.1002/9780470479216.corpsy0467

[8] Ilić, N. Intrinsic and Extrinsic Motivation for Learning English as a Foreign Language. Cambridge, 2014.

[9] Jacques, S. R. Preferences for instructional activities and motivation: A comparison of student and teacher perspectives. Motivation and second language acquisition, 185-211, 2001.

[10] Kanfer, R. Motivational theory and industrial psychology. In M. D. Dunnette \& L. M. Hough (Eds.), Handbook of industrial and organizational psychology (2nd ed., pp. 75170). Palo Alto, CA, Consulting Psychologists Press, 1990.

[11] Kassabgy, O., Boraie, D., \& Schmidt, R. Values, rewards, and job satisfaction in ESL/EFL. Motivation and second language acquisition, 213-237, 2001.

[12] Maslow, A. Deficiency motivation and growth motivation. In M. R. Jones Nebraska symposium on motivation (Vol. 3). Lincoln: University of Nebraska Press, 1995.

[13] Nakata, Y. Intrinsic Motivation in the EFL School Context: A Retrospective Study of English Learning Experiences in Japanese Elementary Schools. THE JOURNAL OF ASIA TEFL, 2009.

[14] Niazi, T., \& amp; Zahid, M. Intrinsic and Extrinsic Motivation for Learning English as a Second Language (ESL) Among PreUniversity Students of Pakistan. International Journal of Research and Innovation in Social Science, 111-124, 2019.

[15] Quadir, M. A comparative study of English and non-English major university students' motivation to learn English oral communication. Cambridge, 2011.

[16] Samejon, Kevin. Extrinsic motivation factors in learning English as a second language. 2015.
[17] Skinner, B. F. Contingencies of Reinforcement. United States of America: Meredith Corporation, 2013.

[18] Tercanlioglu, L. THE NATURE OF TURKISH STUDENTS' MOTIVATION FOR READING AND ITS RELATION TO THEIR READING FREQUENCY. The Reading Matrix, 2001.

[19] Thohir, L. Motivation in a Foreign Language Teaching and Learning. JOURNAL FOR LANGUAGE AND FOREIGN LANGUAGE LEARNING, Vol. 6, Issue, 1, pp. 512-525, 2017. http://dx.doi.org/10.21580/vjv6i11580

[20] Vallerand, R. J., Pelletier, L. G., Blais, M. R., Briere, N. M., Senecal, C., \& Vallieres, E. F. On the Assessment of Intrinsic, Extrinsic, and Amotivation in Education: Evidence on the Concurrent and Construct Validity of the Academic Motivation Scale. Educational and Psychological Measurement, 53(1), 159-172, 1993.

https://doi.org/10.1177/001316449305300101 8

[21] Narendra Bhusakhare, Mausumi Goswami, Ashvinee, Jitesh Singh \& BS Purkayastha, "TEXT ANALYSIS AND SPEECH TO SIGN LANGUAGE TRANSLATION", GLOBAL JOURNAL OF ENGINEERING SCIENCE AND RESEARCHES, [ICRTCET2018], 657-669, 2018

[22] Gulshan and Suman Devi, "LANGUAGE LABORATORY - A GRANDLY ROLE AMONG ENGLISH LANGUAGE LEARNERS", GLOBAL JOURNAL OF ENGINEERING SCIENCE AND RESEARCHES, 5(4), 81-83, 2018

[23] Verplanck, W. S. A glossary of some terms used in the objective study of behavior. Psychological Review, 1-42, 1957. 